\title{
Gap Assessment in the Emergency Response Community
}
JL Barr
A Boek-Peddicord
ER Burtner
WA Pike
BS Minsk

September 2010

Pacific Northwest

NATIONAL LABORATORY

Proudly Operated by Battelle Since 1965 




\title{
Gap Assessment in the Emergency Response Community
}

\author{
JL Barr \\ AM Boek-Peddicord \\ ER Burtner \\ BS Minsk \\ WA Pike
}

August 2010

Prepared for

the U.S. Department of Homeland Security

under U.S. Department of Energy Contract DE-AC05-76RL01830

Pacific Northwest National Laboratory

Richland, Washington 99352 



\section{Summary}

This report describes a gap analysis of the emergency response and management (EM) community, performed during the fall of 2009. Pacific Northwest National Laboratory (PNNL) undertook this effort to identify potential improvements to the functional domains in EM that could be provided by the application of current or future technology. To perform this domain-based gap analysis, PNNL personnel interviewed subject matter experts (SMEs) across the EM domain; to make certain that the analyses reflected a representative view of the community, the SMEs were from a variety of geographic areas and from various sized communities (urban, suburban, and rural). PNNL personnel also examined recent and relevant after-action reports and U.S. Government Accountability Office reports.

This report is not intended to be an exhaustive list of gaps in EM but rather a framework for organizing and analyzing representative gaps uncovered by this effort. The purpose of this report is to present existing EM needs that will inform the development of appropriate technologies to meet these needs in the future. A thorough understanding of these gaps will allow for a more informed approach to applying technology and prioritizing research and development to allow the EM community to improve performance.

The EM community consists of many organizations (local, state, federal, and private). Examples of organizations with EM responsibilities include: the Federal Emergency Management Agency, emergency operations centers, emergency medical services, public health agencies, the U.S. Coast Guard, the U.S. National Guard, law enforcement, public works, search and rescue, the American Red Cross, and the U.S. Department of Transportation. This report discusses some of the key challenges faced by the emergency management community. These challenges are based on needs identified by EM practitioners in 14 interviews conducted by PNNL's Precision Information Environment research team. Interviewees included representatives from the Seattle Fire Department; Seattle Police Department; Seattle Disaster Management Committee Strategic Working Group; Puget Sound Joint Harbor Operations Center; Port of Seattle- Security; Seattle Public Utilities- Security; Benton County, Washington, Emergency Operations Center; Riley County, Kansas, Emergency Operations Center; Kansas State University Bio- and AgroSecurity Experts; and PNNL Northwest Regional Technology Center.

SMEs who were selected based on recommendations of the leadership team from the Northwest Regional Technology Center for Homeland Security interviewed other SMEs and researchers with domain expertise. The format of the interviews was semi-structured, allowing the SMEs to discuss areas of EM that they felt needed the most improvement. Notes from these interviews were compiled and organized into topical areas. Through this effort, PNNL personnel organized the gaps into six categories: Information Collection, Sharing, and Dissemination; Communications; Information Security; Analysis and Decision Support; Situation Awareness; and Knowledge Transfer.

\section{INFORMATION COLLECTION, SHARING, AND DISSEMINATION}

For EM personnel to make accurate and timely decisions, they must have an accurate perception of the situation (situation awareness). The ability to have access to the right information about the situation is essential to this cognitive state. Effective information collection and sharing has been a historic challenge in many arenas, and the problem was highlighted during the interviews. The fast pace and critical nature of EM require the ability to access and share information efficiently and effectively; however, a number of competing factors often make this a challenge. PNNL researchers broke this gap down into two sub-gaps: Data Access and Organizational Information Sharing. 
EM personnel often have difficulties obtaining the information they need. This is due to several fundamental problems: lack of awareness that the information exists; not knowing who controls the information; and the inability to access the information or having access but in a format that is not understandable. Personnel also frequently find that information is not shared across organizations. To address sharing concerns, an appropriate level of trust in the information recipient is required by the information owner.

\section{COMMUNICATIONS}

Emergency communications are essential within and across EM agencies and jurisdictions throughout the lifecycle of an incident. EM communications systems during a catastrophic disaster must operate sufficiently to meet internal and external emergency communication requirements. Research suggests that gaps associated with communications may have organizational, technological, and sociological components (Manoj and Baker 2007). Organizational challenges prevalent in EM deal with a transition from day-to-day centralized decision making to a more dynamic ad hoc organization that emerges with post-disaster relief efforts. The main technological post-disaster challenge is rapid deployment of communication systems for the EM community. Sociological-based communications challenges can arise from public fear, stress, and other emotions aggravated by the lack of information.

PNNL has organized communications gaps identified by SMEs into three categories: verbal communication; communications infrastructure; and communication with the public. The characteristics of verbal communications (e.g., ease of use, perishability, challenge to capture and structure, etc.) make it a natural means for communicating information and a challenge to be as effective as other mechanisms. Communications infrastructure can be impacted in an emergency by too many people vying for the same communication resources (radio channels, cell bandwidth, etc.) and loss of resources due to damage to a portion of the communication infrastructure. Communication with the public was identified by SMEs as an area that could be improved to enhance situation awareness and decision making and to disseminate reliable information to the public, allowing them to better respond to an event.

\section{INFORMATION SECURITY}

Maintaining the appropriate level of security for sensitive information is an important component of emergency management as it allows EM personnel to respond to emergencies without inappropriate use of information by unauthorized parties. Information security, as defined here, can be broadly broken down into two topic spaces: threat-based security and handling-based security. Threat-based security concerns include threats such as cyber attacks (from nondiscriminating malware to targeted attacks). Handling-based security deals with information shared by agencies that will not be handled appropriately, leading to information loss, information confusion, or the dissemination of inaccurate information. Information security measures designed to mitigate threats also make it difficult for those with legitimate operational needs to access information. Varied security protocols at different agencies further complicate the issues of information security and legitimate access to information.

\section{ANALYSIS AND DECISION SUPPORT}

Analysis and decision support are essential to management of the complex environment of an emergency. Analysis involves evaluating information that has been collected and drawing conclusions about the information to enhance decision making. Gaps associated with analysis and decision support were broken into the following categories: information relevance; role ambiguity; decision making with limited information, expertise, resources, and time; and coordinated decision making. Information 
relevance deals with situations in which the value of information may be lost or unrecognized. Role ambiguity exists when individuals or organizations are uncertain of their job duties and level of authority; this leads to increased individual stress and a variety of inefficiencies that negatively impact EM effectiveness. Given the possibility of communications being compromised, unavailability of staff members, and agencies handling their own concerns before communicating with other agencies, decision makers must be able to make the best decisions possible with the information that is available. SMEs stated that they currently lack trusted predictive models and tools that could assist in situations where decision makers are constrained by information, expertise, resources, and/or time. Gaps associated with coordinated decision making relate to difficulties with effective communication within and outside of an organization or group. Coordinated decision making gaps include the inability to effectively communicate to policy makers and not receiving information from organizations that affect communities in one's jurisdiction.

\section{SITUATION AWARENESS}

Situation awareness is a cognitive state that reflects the real-time understanding of an environment and its relation to pertinent goals. Situation awareness has been shown to be significantly related to performance for those who have the technical and operational capabilities to take advantage of it (Endsley 1995). PNNL researchers divided gaps related to situation awareness into three categories: dynamic situations; resource status; and geographic visualization. Dynamic situations often create increasingly complex environments, making it difficult to maintain good situation awareness. SMEs ${ }^{1}$ expressed a need to have better situation awareness of resource status (location and well-being of personnel as well as status of personnel activities) to more effectively manage the situation. Geographic visualization of the situation is hampered by several factors, including expertise required to operate systems, access to geolocated data, and the time required to generate a visualization of the situation.

\section{KNOWLEDGE TRANSFER}

In the EM community, effective knowledge transfer is critical for operations, multiple handoffs, and shift changes during the course of an event. Knowledge transfer is the communication of knowledge between individuals and organizations across a range of domains and time scales (e.g., from shift changes to organizational best practices). PNNL researchers divided knowledge transfer gaps into three categories: shift changes; organizational memory; and training. During shift changes, situation awareness can be degraded or lost due to lack of detailed knowledge transfer. Gaps exist in organizational memory as experienced staff members leave and new staff members join the organization; they also exist in the documentation and understanding of organizational lessons learned and best practices. Training gaps relate to shortcomings in two broad and overlapping categories: training for technical skills and for cognitive skills.

The gaps identified in this report highlight some of the key issues and challenges facing the EM community. By identifying the overarching gaps associated with information collection, sharing, and dissemination; communications; information security; analysis and decision support; situation awareness; and knowledge transfer, PNNL has provided a framework to better understand where technology can contribute to improved EM operations.

\footnotetext{
${ }^{1}$ SMEs from public utilities, fire departments, police departments, and emergency operations centers
} 



\section{Acknowledgments}

The authors of this report would like to acknowledge all of the subject matter experts who donated their time for interviews and follow up questions. Without their input, this report would not have been possible. Subject matter experts from the following organizations donated their time and expertise for this work:

- Benton County, Washington, Department of Emergency Management

- City of Everett, Washington, Office of Emergency Management

- Federal Emergency Management Agency, Region X

- Kansas State University

- Pacific Northwest National Laboratory’s Northwest Regional Technology Center for Homeland Security

- Port of Seattle-Security

- Riley County, Kansas, Department of Emergency Management

- Seattle Disaster Management Committee Strategic Working Group

- Seattle Fire Department

- Puget Sound Joint Harbor Operations Center

- Seattle King County Public Health

- Seattle Police Department

- Seattle Public Utilities-Security 



\section{Acronyms and Abbreviations}

EM

FEMA

GAO

GETS

GIS

IT

NBIC

PNNL

SME

WPS

emergency response and management

Federal Emergency Management Agency

U.S. Government Accountability Office

Government Emergency Telecommunications Service

geographic information system

information technology

National Biosurveillance Integration Center

Pacific Northwest National Laboratory

subject matter expert

Wireless Priority Service 



\section{Contents}

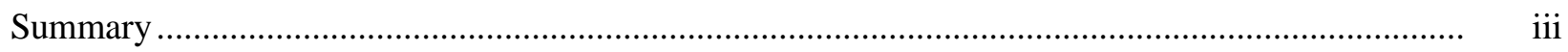

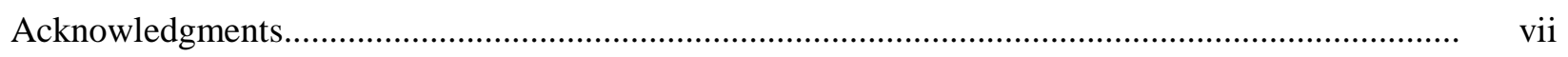

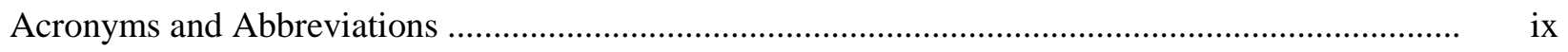

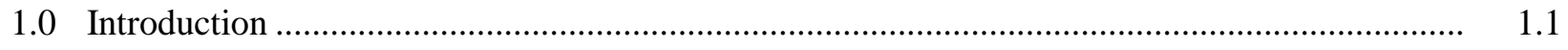

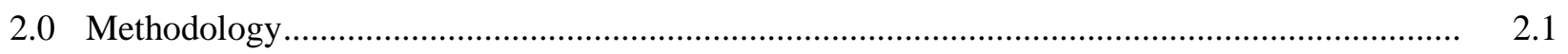

3.0 Emergency Response and Management Gaps ..................................................................... 3.1

3.1 Information Collection, Sharing, and Dissemination ...................................................... 3.1

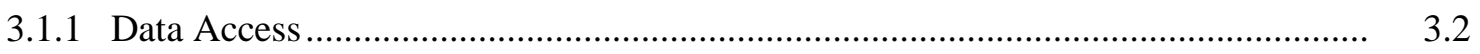

3.1.2 Organizational Information Sharing................................................................ 3.2

3.2 Communications................................................................................................. $\quad 3.4$

3.2.1 Verbal Communication ................................................................................ 3.4

3.2.2 Communications Infrastructure ........................................................................ 3.5

3.2.3 Communication with the Public ..................................................................... 3.6

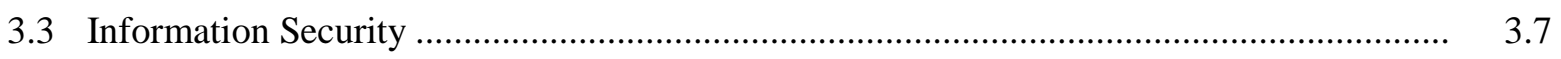

3.3.1 Threat-Based Security …...................................................................................... 3.7

3.3.2 Handling-Based Security ............................................................................. 3.8

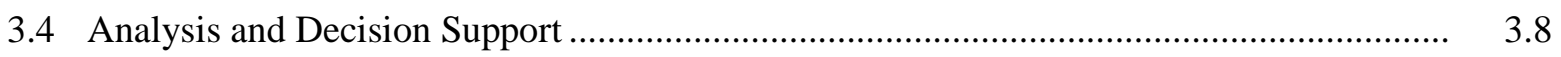

3.4.1 Information Relevance ................................................................................... 3.8

3.4.2 Role Ambiguity ......................................................................................... 3.9

3.4.3 Decision Making with Limited Information, Expertise, Resources,

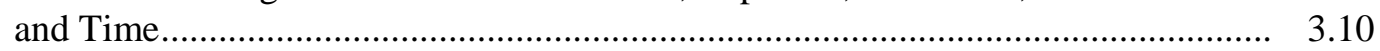

3.4.4 Coordinated Decision Making............................................................................ 3.11

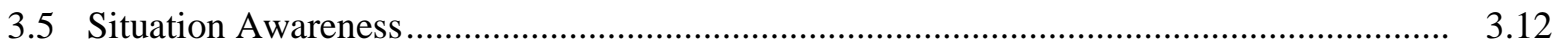

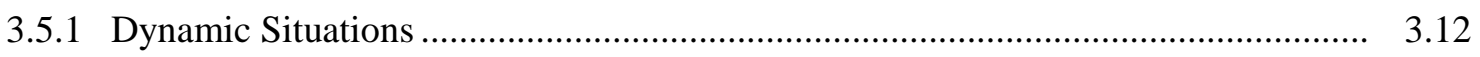

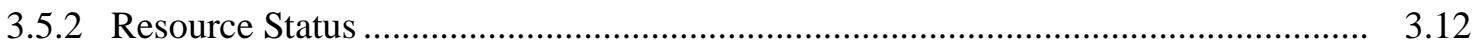

3.5.3 Geographic Visualization ............................................................................. 3.13

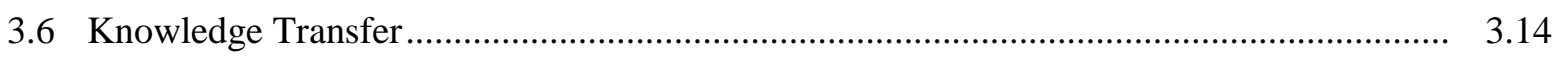

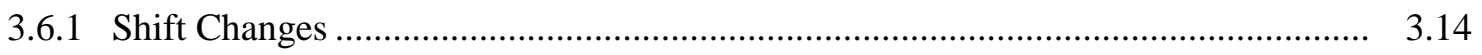

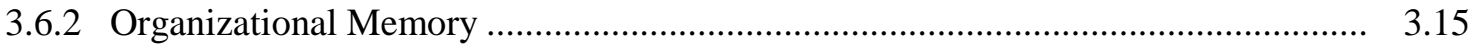

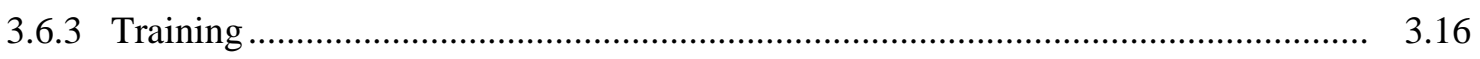

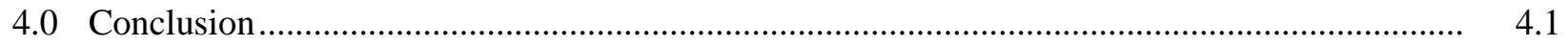

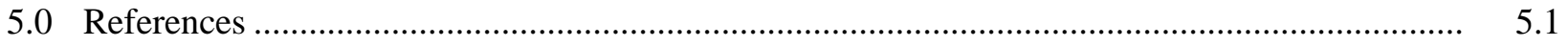

Appendix A - Interview Focus and Sample Questions ......................................................... A.1 


\section{Figures}

3.1 Communications Challenges for Emergency Management Post-Disaster.................................. 3.6

3.2 Example of Integration of GIS Data Layers ..................................................................... 3.13 


\subsection{Introduction}

The first decade of the twenty-first century saw a range of disasters strike worldwide, including terrorist attacks, hurricanes, tsunamis, wildfires, earthquakes, and a pandemic. The immediate and far reaching impacts of these disasters highlight the need for rapid and effective emergency management. The immense tragedy, uncertainty, and fear generated by an emergency underscore the necessity for effective regional preparation, response, recovery, and restoration.

This project focuses on emergency management because of the crucial role played by emergency response and management (EM) and response in saving lives and property and in mitigating the impacts of disasters. Emergency management is the discipline and activities of dealing with and avoiding risks. Its role in the community is to assess and prepare for current risk conditions, to proactively take steps to mitigate those risks, and to respond/recover should an emergency situation occur. The EM community consists of many organizations (local, state, military, nonprofit, federal, and private). Examples of organizations that perform EM functions include: the U.S. Federal Emergency Management Agency (FEMA), fire, communications (i.e., 911), departments of emergency management (city, county, state), emergency medical services, public health, U.S. Coast Guard, U.S. National Guard, law enforcement, public works, search and rescue, the American Red Cross, and the U.S. Department of Transportation. This project aims to support emergency managers in appropriate and efficient planning, mitigation, response, and recovery efforts, and to help them effectively leverage their resources when responding to a disaster. This will be accomplished by developing future work environments for emergency management. These work environments, called precision information environments, will provide tailored access to information and decision support capabilities that adapt to the varying users and phases of emergency management. A precision information environment will provide analysis and simulation capabilities through novel interactions that transform planning, communication, and decision making by first responders, policy makers, and the public.

This report discusses some of the key challenges faced by the EM community. These challenges are based on needs identified by EM practitioners in 14 interviews conducted by Pacific Northwest National Laboratory's (PNNL’s) Precision Information Environment research team. Interviewees included representatives from the following:

- Benton County, Washington, Department of Emergency Management

- City of Everett, Washington, Office of Emergency Management

- FEMA, Region X

- Kansas State University

- PNNL's Northwest Regional Technology Center for Homeland Security

- Port of Seattle-Security

- Riley County, Kansas, Department of Emergency Management

- Seattle Disaster Management Committee Strategic Working Group

- Seattle Fire Department

- Puget Sound Joint Harbor Operations Center 
- Seattle King County Public Health

- Seattle Police Department

- Seattle Public Utilities-Security

The challenges and needs discussed by interviewees have been analyzed and distilled into fundamental gaps that are common to multiple EM agencies. Due to the semi-structured format of the interviews, different groups focused on different needs. The purpose of this gaps report is to present existing EM needs that will inform the development of appropriate technologies to meet these needs in the future. 


\subsection{Methodology}

Methodology consisted of two major activities: interviews with EM professionals and a literature review. A series of 14 interviews were conducted with EM subject matter experts (SMEs). These experts were selected based on recommendations of the leadership team from the Northwest Regional Technology Center for Homeland Security, and the experts interviewed SMEs and researchers with domain expertise. To make sure a sample of EM organizations were represented throughout the country, emergency managers from urban, suburban, and rural areas (respectively from Seattle, Washington; Benton County, Washington, and Riley County, Kansas) were interviewed. Interviews with SMEs were conducted in person and lasted between 45 and 90 minutes. During the interview, the SME was asked to provide background on his/her organization and his/her function within the organization. The format of the interviews was semi-structured, allowing the SMEs to discuss areas of EM that they felt needed the most improvement. Notes from these interviews were compiled and organized into topical areas. The areas in which there was agreement from SMEs are detailed in Section 3. A targeted review of articles, workshop proceedings, after-action reports, and U.S. Government reports was performed to examine whether the EM needs identified in SME interviews were indicative of needs in the larger EM community. 



\subsection{Emergency Response and Management Gaps}

The purpose of this section is to document the gaps that were identified through the interviews with SMEs in EM. A corresponding literature review provides further details in the identified gap areas. These gaps are presented with no priority in their order. In each section, the gap is defined and details explaining the gap and/or examples illustrating the gap are presented. Relationships between gap areas are explicitly called out.

\subsection{Information Collection, Sharing, and Dissemination}

For EM personnel to make accurate and timely decisions, they must have "situation awareness," an accurate perception of the situation that they are facing (detailed in Section 3.5). Essential to good situation awareness is the ability to provide relevant and timely information to decision makers. Effective information collection and sharing has been a historic challenge in many arenas, and the problem continued to be highlighted during the recent interviews (GAO 2009a).

The fast pace and critical nature of EM require the ability to access and share information efficiently and effectively; however, a number of competing factors often make this a challenge. One factor is the ability to access data when needed and to effectively share information across organizations. EM personnel often have difficulties obtaining the information they need for an effective response, and they frequently find that information is not shared across organizations. To address concerns in this area, mechanisms must be put in place to make sure that information sharing is possible and that an appropriate level of trust in handling and storage of information from the information recipient is required.

The goal of addressing gaps in information collection, sharing, and dissemination is to improve regional preparedness, to create a robust operational picture, and to better assign appropriate information to the right resource. This enables shared situation awareness with higher overall efficiency and effectiveness - the best resources for the task have the necessary information, and there is less duplication of effort (GAO 2009b). For enhanced and sustainable collaboration, which are necessary for information sharing and dissemination, the U.S. Government Accountability Office (GAO) found in its report on practices that aid and sustain collaboration (GAO 2005) that it is critical that organizations:

- articulate a common outcome

- establish mutually reinforcing or joint strategies

- identify and address needs by leveraging resources

- agree on roles and responsibilities

- establish compatible policies, procedures, and other means to operate across agency boundaries

- develop mechanisms to monitor, evaluate, and report on results.

As collaboration is enhanced, information collection, sharing, and dissemination should also improve. The following sections will discuss the gaps that currently impede collaborative use of shared information. 


\subsubsection{Data Access}

Information collection for EM can be hampered by difficulties in locating and accessing important information. This is due to several fundamental problems: lack of awareness that the information exists; not knowing who controls the information; and inability to access the information or having access but in a format that is not understandable or intuitive. SME interviews ${ }^{1}$ revealed that there is difficulty accessing relevant data when they are not in a format compatible with the tools that are being employed. Often, data are contained in nonstructured or semi-structured data stores that cannot be easily interpreted or imported by tools used in the EM community (e.g., WebEOC ${ }^{\circledR}{ }^{2}$, OpsCenter, Geographic Information System tools, etc.). These types of data stores can contain a wide range of information important to EM operation, such as tasking, situation reports, resource status, maps, infrastructure status, incoming call information, and so forth. Another example of data access limitations affecting EM operations is in the information provided by sensor systems, which are becoming more prevalent and essential to EM. Sensor systems provide EM the ability to monitor and collect information surrounding domain-specific concerns (e.g., flood detection, critical infrastructure protection, etc.). Access to the information provided by sensor systems is critical to the EM community's ability to monitor emergency situations. SMEs ${ }^{3}$ stated that it is difficult to deploy sensors quickly, that much of the sensor data are contained locally and are not always stored, and that monitoring of critical infrastructure is resource-constrained, often without a staff member available to provide continuous monitoring. Without the ability to have on-line, real-time sensor systems, decision makers must rely on human resources in the field to read and interpret sensor output. This keeps those resources that are relaying sensor information from performing other essential functions. Also, it is impractical to digest all data from various sensors in a standardized fashion when sensor information is communicated over radio or phone (as is often the case with offline sensors). Although sensors provide valuable information, the inability of the EM community to efficiently access the information limits the ability of the EM community to fully utilize that information.

\subsubsection{Organizational Information Sharing}

EM organizations leverage their resources and generate better situation awareness for the community when they collaborate and share information (GAO 2005, 2009c). The amount of information shared between organizations can vary widely based on region and organization. Typically, the degree to which organizations share information is based on personal relationships and the history of trust built around relationships (GAO 2009c). These informal relationships typically develop between individuals and are not easily or quickly recreated if the trusted party is not available or has left an organization. Many regions rely heavily on established informal communications networks and do not have processes to facilitate formal information sharing. While informal networks can be highly effective, the movement of information is hampered when a trusted party is unavailable. Informal networks also do not work when information movement is automated (automation allows information to be disseminated quickly to multiple

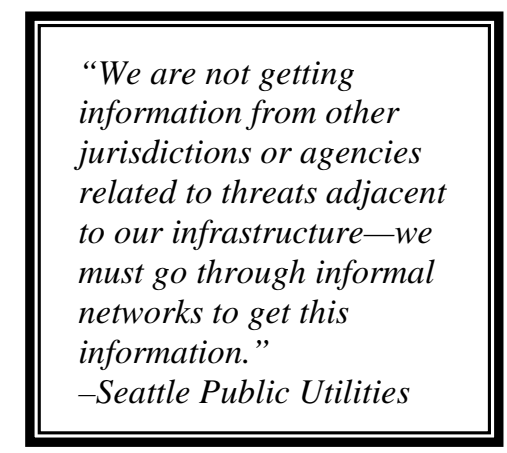

\footnotetext{
${ }^{1}$ SMEs from port authority, fire departments, police departments, and Seattle Disaster Management Committee Strategic Working Group

${ }^{2}$ WebEOC is a registered trademark of ESI Acquisition, Inc.

${ }^{3}$ SMEs from public utilities, port authorities, fire departments, police departments, and Seattle Disaster Management Committee Strategic Working Group
} 
parties with limited input [e.g., multiple phone calls, emails, etc.] from the information provider). Before establishing rules for information sharing, information providers' concerns about others' need for and use of shared information must be addressed. This adjudication process will most likely be unique for each region as roles and responsibilities for organizations vary by region.

An instance of an informal network's relationship to information sharing is illustrated by an example from GAO (2009c). The report showed how local organizations did not receive information from other local organizations or federal partners because they were too resource limited (staff and funding) to participate in regular meetings with their federal partners (U.S. Customs and Border Protection, U.S. Immigration and Customs Enforcement, and the Federal Bureau of Investigation). These regular meetings were the conduit used to share information, establish face-to-face contact, and build trusting relationships with and between locals (GAO 2009c). Ultimately, the lack of relationships between organizations led to the inability of local organizations to obtain information from federal agencies.

Another example cited by GAO (2009d) detailed issues surrounding information-sharing between organizations. The organizations in this study were the National Biosurveillance Integration Center (NBIC) and its partner organizations. The goal of the NBIC is to help with early detection and situation awareness associated with a biological event by integrating information from multiple sources. Partner agencies were unclear regarding the role of NBIC and the benefit of sharing information with the organization and therefore were reluctant to do so. The report states that

in interviews with partner agencies, GAO encountered widespread confusion, uncertainty, and skepticism around the value of participation in the interagency community, as well as the mission and purpose of NBIC within that community. Further, interviews with agency officials demonstrated a lack of clarity about roles, responsibilities, joint strategies, policies, and procedures for operating across agency boundaries.

Due to lack of familiarity with NBIC and its mission, participating agencies did not actively engage NBIC in information-sharing activities, resulting in the NBIC not having the information fundamental to accomplish its mission.

The EM community has many concerns about how information sharing should be executed. Information providers do not always understand what they have that others need, and information receivers do not always articulate or differentiate between want and need. Decision makers require timely, relevant information in easy-to-read formats. Information-sharing issues facing decision makers include receiving irrelevant information that they must sort through, relevant information in an unusable format (e.g., model data provided without structured vocabulary, or ontology), and/or old information. Concerns about information security (discussed in Section 3.3) can prevent information from being shared or may require additional measures that slow the sharing process, such as hand carrying information. While such security measures are often necessary to protect sensitive information from being made public, these same measures can impede the flow of important, time sensitive information.

According to SMEs from a federal EM agency, their agency protocol is to hand deliver data stored on electronic media to other agencies that need the information-which is not a convenient method, especially in an emergency. Once those data are delivered, there is no guarantee that another agency would be able to understand the data received, especially if it contained terminology, layers or symbols 
specific to the originating agency. In this example, both the time delay and the ability to understand what was delivered make the data considerably less valuable than if these issues were addressed.

The examples discussed above highlight some of the key challenges in sharing information between organizations. Most SMEs interviewed identified the importance of interorganizational information sharing but noted the practical difficulties often associated with sharing information.

\subsection{Communications}

Emergency communications are essential within and across EM agencies and jurisdictions throughout the lifecycle of an incident. According to GAO (2009e)

agencies' communications systems during a catastrophic disaster must first be operable, with sufficient communications to meet internal and emergency communication requirements. Once operable, they then should have communications interoperability whereby public safety agencies (e.g., police, fire, emergency medical services) and service agencies (e.g., public works, transportation, hospitals) can communicate within and across agencies and jurisdictions in real time as needed.

PNNL researchers have identified three gap areas in emergency communication: verbal communication; overwhelmed communications; and communication with the public. Research suggests these gaps may have technological, sociological, and organizational components (Manoj and Baker 2007). According to the research, the primary technological challenge after a disaster is rapid deployment of a communications infrastructure for EM. This is true for a partially destroyed communications system, completely destroyed communications system, or in situations where communications infrastructure does not exist (e.g., remote regions, etc.). Important social challenges relating to communications also need to be considered. These challenges include understanding human behavior (i.e., behavior related to fear or stress) and its impact on emergency communication. Fear, stress, and other emotions are mitigated with periodic information updates (Manoj and Baker 2007). Most importantly, emergency communication tools for the public must be "affordable, available, and applicable during their day-to-day life” (Manoj and Baker 2007) for use during a crisis.

\subsubsection{Verbal Communication}

A primary source of information in EM is verbal communication (e.g., 911 calls, television and radio press, responder communications, etc.). The characteristics of verbal communications (e.g., ease of use, perishibility, etc.) make it at once a natural means for communicating information and a challenge to be as efficient or effective as other mechanisms. One such challenge is that verbal communication accessed through various communication modalities is a challenge to capture and structure. Another related problem is that verbal communication modalities (radio, phone, etc.) are not always ideal for

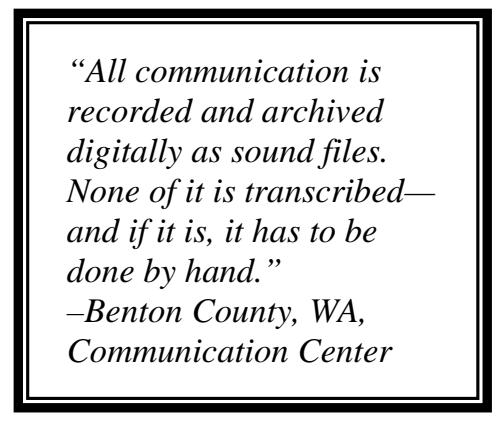
an operational environment. In interviews and through literature review, it was apparent that many people in EM valued voice communication; it is trusted and has been shown to be effective in the past. Due to its proven utility, voice communication should not be eliminated from the environment but should 
be used where it is best suited (e.g., instances where information only needs to be communicated once to a single individual or group, etc.). Other modalities should take over in situations where voice communication is insufficient; for example, when people are overwhelmed and need access to facts and information in a format that can be stored and easily and effectively shared.

\subsubsection{Communications Infrastructure}

The potential for communications systems to be overwhelmed poses a serious threat to efficient information sharing in an emergency. Two substantial communications concerns that can arise from certain emergency situations are: too many people vying for the same communication resources (radio channels, cell bandwidth, etc.) and loss of resources due to damage to some portion of the communication infrastructure (Figure 3.1). The first is a concern because access to communications channels is widely available but much of the information shared may not be important, especially with regard to EM activities. This is of particular concern with radio channels, where access is open and equal among many different parties. It is of less

\begin{tabular}{|l||}
\hline "In one instance, while \\
deploying a mobile \\
communications system, the \\
communications specialists \\
were afraid to touch \\
complex equipment out of \\
fear of disrupting \\
communication across the \\
region." \\
-Seattle Police Department \\
\hline
\end{tabular}
concern for telephony services, which have tiers of priority for emergency services such as Government Emergency Telecommunications Service (GETS) and the Wireless Priority Service (WPS) and can be rerouted for connection, assuming that local communications infrastructure is still functional (GAO 2009f).

Figure 3.1 illustrates how a disaster can lead to communications breakdown. In a disaster such as an earthquake, the communications infrastructure may be damaged such that facilities supporting communication are damaged and responders are unable to communicate. 


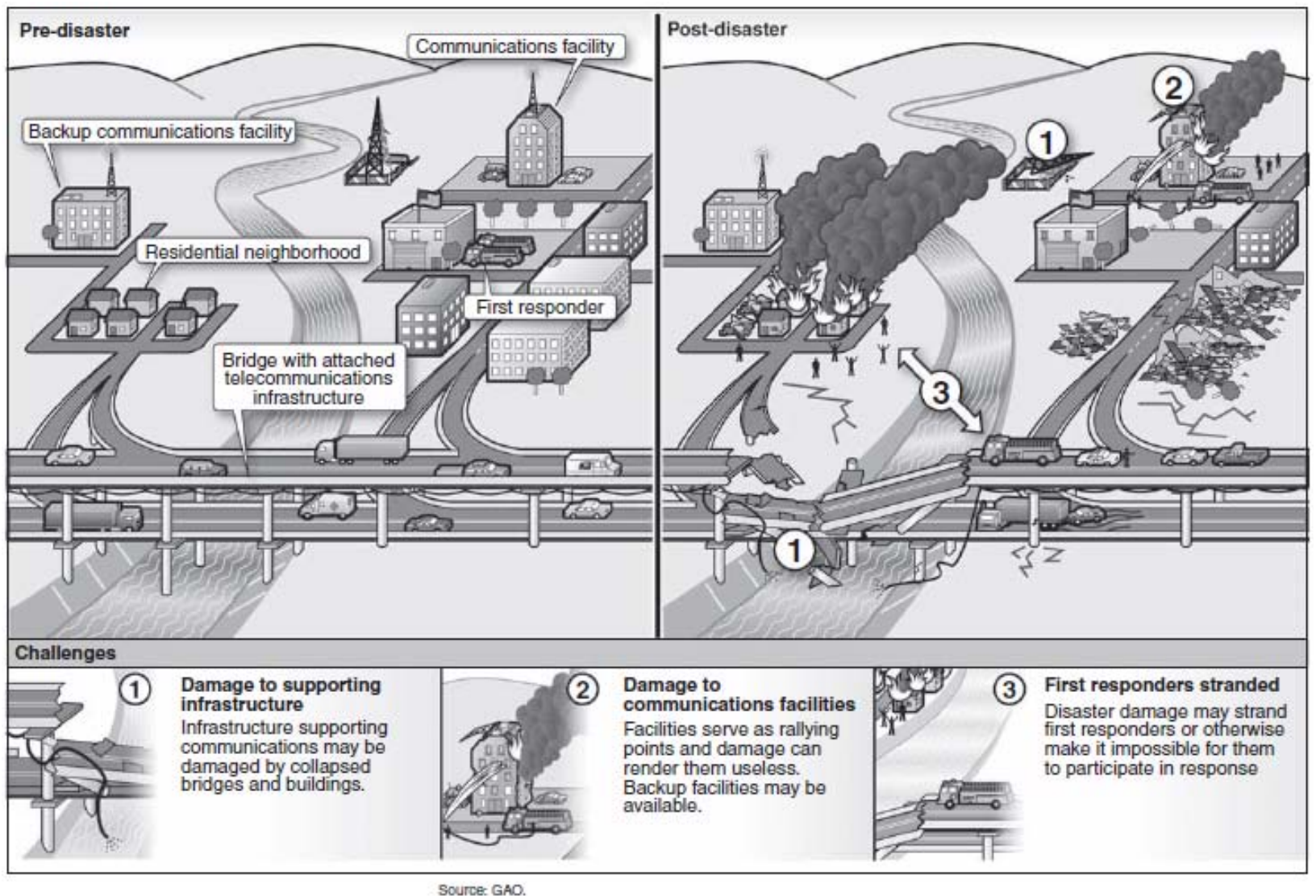

Figure 3.1. Communications Challenges for Emergency Management Post-Disaster (GAO 2009g)

The inability to effectively communicate information can lead to duplication of effort to reproduce missing information in situation awareness. A Seattle Fire Department SME discussed witnessing this duplication of effort in the aftermath of Hurricane Katrina as it applied to multiple agencies doing redundant damage assessments of the same areas. The GAO stated about Katrina that "this lack of communication made it difficult for senior military leaders to determine which missions had been completed, which were still ongoing, and what new missions may have surfaced” (GAO 2006). Whether too many personnel are using limited resources, or some communication sources are down due to the emergency, the ability to collect and share crucial information is limited if communication systems are overwhelmed.

\subsubsection{Communication with the Public}

Information sharing between EM and the public serves two key purposes: 1) obtaining good information from the public can enhance situation awareness and decision making; and 2) disseminating reliable information to the public will allow it to better respond to an event. EM's proper engagement with the public when responding to an

"We need the ability to communicate a message to our audience quickly, easily, and in a way that everyone understands and has the technology to manage."

-Seattle King County

Public Health emergency event can enhance situation awareness for both the public and the EM community as well as ease the public's fear and uncertainty. The public has the potential to be an invaluable source of information (i.e., needs, situation, and environment) in an emergency. Concurrently, the public must be 
kept informed during an emergency. SMEs ${ }^{4}$ stated that EM currently lacks effective tools for collecting, vetting and, understanding information from the public and keeping the public informed with timely, consistent, accurate, and useful information during an event.

One example of effective information sharing with the public occurred during the 2007 Southern California wildfires when a public radio station's website displayed geolocated feeds from a social networking site, providing enhanced situation awareness for the public (Poulsen 2007).

\subsection{Information Security}

Maintaining the appropriate level of security for sensitive information is an important component of EM, allowing EM personnel to respond to emergencies without information being used inappropriately by unauthorized parties. Information security, as defined here, can be broadly broken down into two topic spaces: threat-based security and handling-based security.

\subsubsection{Threat-Based Security}

Information security concerns and operational needs are often at odds. With concerns of various types of cyber attacks (from nondiscriminating malware to targeted attacks), information technology staff members have an interest in providing a high degree of security. Information security threats could disrupt critical operations, such as those supporting critical infrastructure, national defense, and emergency services. Additionally data could be added, modified, or deleted for purposes of fraud, subterfuge, or disruption (GAO 2010a) (GAO d). Information security to mitigate these types of attacks typically involves locking user permissions on local machines and employing highly restrictive network firewalls. While these measures mitigate cyber attacks, they also make it difficult or impossible for those with legitimate operational need outside of the firewall to gain inbound access to protected systems or outbound access through the firewall to trusted systems. Rules imposed for information security can also impede information sharing and access. Varied security protocols at different agencies further complicate the issues of information security and legitimate access to information.

GAO (2010a) found that the most prevalent types of cyber incidents were "unauthorized access" (logical or physical access to a system without permission), "improper use" (a violation of acceptable computing use policies), and "unresolved” (potentially malicious or anomalous activity warranting further review). In this report, the GAO found that federal agencies

did not consistently identify and authenticate users to prevent unauthorized access; enforce the principle of least privilege to ensure that authorized access was necessary and appropriate; establish sufficient boundary protection mechanisms; apply encryption to protect sensitive data on networks and portable devices; and log, audit, and monitor security-relevant events.

These findings reveal that agencies require continued vigilance to properly protect their data and systems from current and future cyber threats.

\footnotetext{
${ }^{4}$ SMEs from public utilities, fire departments, police departments, and Seattle Disaster Management Committee Strategic Working Group
} 
While vigilance is needed to fend off pervasive cyber attacks and the potential damage to EM operations and critical infrastructures that they affect, it is still crucial for EM personnel to have the ability to access the information that allows them to best perform their duties (Section 3.1).

"We need the ability to consolidate, organize, and prioritize."

-Puget Sound Joint Harbor Operations Center

\subsubsection{Handling-Based Security}

Organizations are responsible for making sure that their staff handles sensitive information appropriately. Sharing between agencies is often limited by concerns that sensitive information will not be handled appropriately or in the same manner as the owning agency. A GAO report on critical infrastructure protection concluded that a lack of trust in the Department of Homeland Security and concern that sensitive information may be compromised are frequent barriers to the private sector sharing information with the federal government (GAO 2007a).

The GAO observed that handling concerns are also an interagency issue:

Participants repeatedly raised concerns about trusting NBIC with data, and participants also expressed concern that NBIC would reach the wrong conclusions or disseminate erroneous data or reports ... These comments generally noted concerns that NBIC's lack of contextual sophistication could lead to confusion, a greater volume of unnecessary communication in the biosurveillance environment, or even panic (GAO 2009d).

These examples demonstrate agencies' concern that information they share will be handled inappropriately, leading to information loss, confusion, or the dissemination of inaccurate information.

\subsection{Analysis and Decision Support}

Strong analysis and decision support are essential to managing the complex environment of an emergency. Analysis involves evaluating information that has been collected and drawing conclusions about the information to enhance decision making. Analysis and decision support also help people evaluate decision consequences. Understanding the current state of events as well as the impacts and benefits resulting from different courses of action aids decision making and allows for a more complete understanding of a situation. Methods for conducting analysis and decision support include modeling and simulation, predictive analytics, online analytical processing, and case-based reasoning, among others.

\subsubsection{Information Relevance}

There are three areas in which the information relevance may be lost or unrecognized due to existing gaps. The first area, information overload, exists when an overwhelming amount of information exists such that users may not be able to identify or efficiently access relevant information. Second is information in an unusable format (e.g., a file format that is not supported by the recipients systems). Third is the tendency to allow new information to supplant older important information. Each of these areas highlights gaps in the ability to add value to information. 
There is an unprecedented amount of information available to EM personnel. However, much of the available information may be neither relevant nor unique to a specific emergency event. Decision makers want to filter through unnecessary information to find what is needed. This is time-consuming and fatiguing for EM personnel, and it hinders the timely decision making during a crisis (GAO 2007b).

Fusion centers are organizations tasked with gathering and analyzing information and sharing the resulting intelligence with federal, state, and local partners. The GAO studied numerous fusion centers around the country and noted that

officials at 30 of the fusion centers found the multiple systems or heavy volume of often redundant information a challenge to manage. Officials in 18 fusion centers said that they had difficulty with what they perceived to be the high volume of information their center receives, variously describing the flow of information as "overwhelming," "information overload," and "excessive." For example, officials said that center personnel must sort through the large amount of information, much of which is not relevant to the center, to find information that is useful or important to them (GAO 2007b).

In addition to having too much information, sometimes the format of information, regardless of its importance, may not be relevant, understandable, or usable. When users cannot understand or use data because of format, is those data are not valuable to them, regardless of applicability. Important information may be lost or ignored in such cases, handicapping EM personnel.

Finally, there is a tendency to focus on the newest information and ignore older-but still relevantinformation. Such historical information must remain available as a reference to contextualize and, in some cases, validate newer information. If older information is discarded, those working on analysis and decision support may lose potentially valuable content.

Supplanting older information with newer, noncontextualized information was noted by an SME from agricultural security during an interview. During a multiagency agroterrorism exercise, intelligence indicated transportation of explosives. Later in the exercise, other intelligence indicated an imminent attack on the food supply, independent of the transportation of explosives. As the exercise participants worked on the food-supply threat, they halted efforts to track the transportation of explosives - and they didn't resume resolution of the initial threat. This example demonstrates the tendency to focus on new information and to allow older information to be neglected. However, older information often is critical to providing context or historical background and must be stored or maintained so it can contribute to effective analysis and decision support.

\subsubsection{Role Ambiguity}

Role ambiguity exists when individuals or organizations are uncertain of their job duties and level of authority - this is typical with new and unknown situations (McShane and Von Glinow 2000). Role ambiguity can be seen in the EM community in unplanned or unexercised situations and in situations where authority is transferred to an organization that does not drill or exercise with the community. Role ambiguity in emergency situations has negative effects for both individuals and the larger EM effort. These negative effects include:

- increased stress for individuals who are unsure of their duties, expectations, and authorities 
- inefficiencies associated with duplicating efforts (e.g., multiple organizations making sure the same area has been evacuated)

- inefficiencies associated with not understanding, and therefore not utilizing, the capabilities of individuals or organizations

- inefficiencies associated with determining organizational roles and responsibilities during an emergency event (i.e., taking up valuable time and lacking the ability for deliberation that is possible in the calm of normal operations).

“There is currently no ability to take vast information, analyze, and distill it for strategic decision making such as looking at impacts of disaster on a community or an economy."

-Puget Sound Joint

Harbor Operations Center

A considerable amount of work has been completed recently to make sure that EM organizations and personnel understand their roles in events. Efforts such as transitioning from the National Response Plan (DHS 2004) to the National Response Framework (DHS 2008a) were designed and conducted primarily so that roles were understood (GAO 2008a). Roles, such as leading and supporting agencies, are outlined in the National Response Framework and its emergency support function annexes. States and cities also follow the National Response Framework to help define roles and organization during an event. The National Response Framework is being implemented federally and to a lesser extent locally, but awareness of private institutions and nongovernmental organizations (DHS 2008b) and the roles they play may not be fully realized at either the federal or local level. One reason for this is that FEMA (under the National Response Framework) is responsible for coordinating with these organizations but does not have sufficient resources to meet this responsibility (GAO 2008b).

One domain where there is a lack of clearly understood roles is chemical, biological, radiological, nuclear, and explosive events (GAO 2008c, 2009d, 2010b, 2010c). For example, the GAO concluded (2010b) that a lack of guidance on federal responsibilities and activities has left local and state EM organizations confused about which federal agency to turn to for assistance when recovering from an attack that requires removal of radioactive materials from buildings and infrastructure. Another example is how partner organizations constrain NBIC's ability to disseminate intelligence about biological events (GAO 2009d). This occurred because partner organizations prevented their SMEs from communicating with NBIC in the early stages of a biological event, not recognizing the role or the value of the NBIC effort.

There is also considerable role ambiguity surrounding cyber security event. The U.S. Comprehensive National Cybersecurity Initiative was created to prepare and defend against current and future cyber threats. The Cybersecurity Initiative faces several challenges in defining cyber security roles and responsibilities for federal agencies, in distinguishing overarching coordination responsibility, and in establishing measures of effectiveness. The Cybersecurity initiative has not yet developed measures of the effectiveness in meeting its goals (GAO 2010d).

\subsubsection{Decision Making with Limited Information, Expertise, Resources, and Time}

Decisions made in an EM environment must be timely and based upon the information available. Given the possibility of compromising communication, the unavailability of staff members, and other agencies handling their own concerns before communicating with other agencies, decision makers must 
be able to make the best decisions possible with the information that is available. They may choose to change direction if necessary or possible as new information becomes available.

The amount and type of information the interviewees desired was wide ranging; many reported lacking tools that could mitigate missing information or expertise. For example, it would be useful for

"Significant time is spent by people unfamiliar with one another figuring out who has authority to do what, who should do what, role of courts and judges." -Seattle Police Department first responders to be able quickly predict the behavior of hazardous plumes in various environments so they could better plan incident response (GAO 2008c). Evacuation planning was often used as an example by SMEs that demonstrated gaps in this topic space. Interviewees expressed a desire for better information before they determined where and when to evacuate people from their homes and businesses. Law enforcement personnel stated in an interview that it would be useful to have social predictive models to be better able to anticipate reactions under various emergency scenarios (evacuation, crowd control, etc.). The current tools for solving these problems require expertise, are time consuming to run, and do not have as much detail and accuracy as desired.

From the interviews, it appears that predictive capabilities would be of even greater value to rural areas where the EM community is largely volunteer based and has fewer staff members responsible for more job functions. In this community, it is more difficult to have the amount of specialization in job function which typically leads to expertise in those functions. These communities often rely upon incident management teams to provide the staffing and expertise to supplement local resources in large scale incidents (GAO 2007c, 2009h). However, national incident management teams may take up to 12 hours to arrive on scene, which is a critical time period for response (GAO 2007c).

"Lack of collaboration hampers the utilization of resources, especially between regional, federal, and jurisdictional organizations." -Seattle Police Department

This desire for expertise/predictive capability extends from domains that involve command and control to those of logistics and recovery. The interviewers heard from SMEs ${ }^{5}$ that resource allocation is complex and that it is difficult to assess what resources will be needed, where they will be needed, and where they are currently available. SMEs also noted that cost sensitivity needed to be accounted for in resource allocation.

Hazard mitigation is an area of EM lacking predictive modeling capabilities. Several SMEs expressed an interest in the capability to select, justify, and quantify mitigation efforts. During the research, PNNL investigators did not note any technologies that performed these tasks.

\subsubsection{Coordinated Decision Making}

Gaps associated with coordinated decision making relate to difficulties with effective communication within and outside one's organization or group. SMEs from emergency operations centers explained that without coordination, organizations from one jurisdiction sometimes have to quickly respond and readjust strategies based on what organizations in neighboring jurisdictions choose to do if not previously informed or aware of those plans. The specific example cited by emergency operation center managers

\footnotetext{
${ }^{5}$ SMEs from public utilities, fire departments, police departments, FEMA, and departments of emergency management
} 
involved issues associated with the deployment of H1N1 vaccine in the fall of 2009. In this case, each county had various plans that affected other counties. Residents of one county would flock to another that was distributing vaccine, creating long wait times at clinics.

The ability to communicate consequences and tradeoffs associated with various decisions with appropriate metrics to those outside the emergency management community (e.g., policy makers) is difficult. Effectively communicating decisions in a common language aids in establishing trust which, in turn, assists public understanding of roles and responsibilities.

\subsection{Situation Awareness}

Situation awareness is a cognitive state that reflects the current, real-time understanding of an environment and its relation to pertinent goals. Endsley (1995) describes situation awareness as having three components: perception of elements in the environment within a given time and space; comprehension of the current situation; and the projection of status in the near future. Comprehensive understanding of a situation reduces uncertainty during decision making. Common situation awareness underlies effective communication and helps put individual activities in a broader context (Gorman et al. 2006). Situation awareness has been shown to be significantly related to performance for those who have the technical and operational capabilities to take advantage of it (Endsley 1995).

\subsubsection{Dynamic Situations}

It becomes increasingly difficult to maintain good situation awareness as the complexity and dynamics of the environment increase. One challenge in complex emergency situations where the environment is constantly changing is change detection (Endsley 1995). A concern with technologies assisting with situation awareness is that they provide sufficient information to understand both the situation and any change of state without taxing the abilities of humans to act as timely decision makers (Endsley 1995).

Another concern of SMEs interviewed was getting relevant information in a timely manner. Often, an understanding of what is happening outside one agency's purview is relevant to a larger understanding of the event and can assist that agency in making more informed decisions. During an emergency, this type of information is typically transferred between agencies once or twice a day in the form

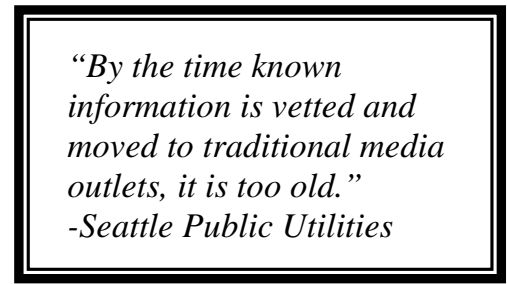
of situation reports or after an event in the form of a final or after action report. According to GAO (2009d), finished products represent a final analysis of the raw data and have been reviewed and approved by the agency leadership for general dissemination to interested parties. These products (final reports) are generally useful for providing context but not for early detection of an event because they are not generated in a timely manner and focus on past events (GAO 2009d).

\subsubsection{Resource Status}

In many emergency environments, resources are tracked using white boards or static maps. Electronic systems, such as Computer Aided Dispatch, can track vehicles associated with personnel. However, these systems do not track to the level of the individual. Many electronic systems developed 
for EM account for and track resources through manual entry into a table based system. SMEs, ${ }^{6}$ especially those responsible for command, expressed a need to have better situation awareness with the respect to location, well being of personnel, and status of tasks and activities that those personnel are responsible for. They also explained that it was hard to account for "unmanaged" resources such as selfdeployed responders and noninventoried resources (e.g., volunteers) in an event. Finally, better situation awareness of infrastructure and resources (e.g., roads, utilities, shelters, etc.) was desired. Examples were noted where firefighters lost their lives while trapped in a backfire because others were unaware that they were in the area.

\subsubsection{Geographic Visualization}

Geographic information systems (GISs) have the ability to integrate heterogeneous information about a physical location (Figure 3.2), which can lead to better-informed decisions and a more effective and timely response in emergency situations. It is now possible to integrate information from many disparate GIS databases to develop rich analytical information on almost any topic associated with physical

"Mapping technologies should address who is not getting served in a disaster."

-Seattle Fire Department locations. Data once collected and used only for a single purpose now have much broader applications (GAO 2003). To realize the benefits that GIS could provide to the EM community, challenges to data sharing and integration need to be addressed (GAO 2003).

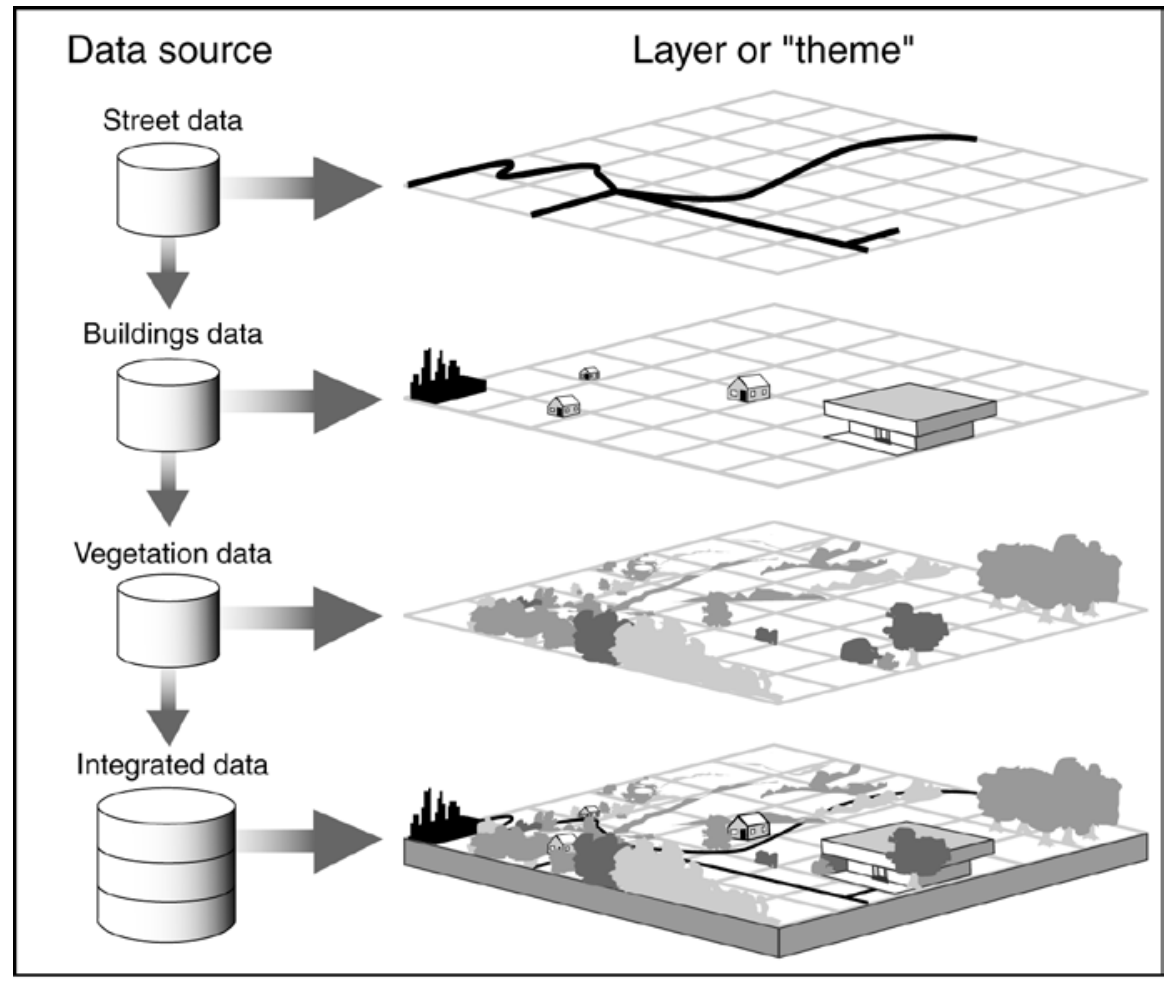

Source: GAO

Figure 3.2. Example of Integration of GIS Data Layers

\footnotetext{
${ }^{6}$ SMEs from public utilities, fire departments, police departments, and emergency operations centers
} 
According to GAO (2003), local governments often possess the most recent and highest resolution geographic data. These data often are used for specific purposes and may be difficult to repurpose. It takes a considerable amount of effort to reconcile data sets to make them usable in an integrated database (GAO 2003). The GAO's perspective was confirmed by SMEs who had issues integrating with other jurisdictions and federal systems.

One of the difficulties in integrating geospatial data from various sources is the lack of common geospatial standards. Developing these standards can be a complex and time-consuming effort. The GAO found that the number of types and complexity of geospatial data make standard development a challenge (GAO 2003). For geospatial data to be effectively shared, standards must be developed that allow interoperability and integration of the many disparate formats of data that are currently collected for each theme and subtheme of geospatial information. A major concern is that agencies would be reluctant to adopt framework data standards. The GAO concluded in its report on geographic information systems that most federal agencies have not participated in a standards-development process that will likely result in proposed standards not meeting the agencies' individual needs. Once new GIS standards are in place, agencies could be faced with a costly migration to the new standard. Reluctance to migrate also stems from the substantial investments made to independently develop geospatial systems with formats and standards that meet individual agency needs (GAO 2003)

Aside from the issues of access to information for GIS systems, the systems themselves have shortcomings for use by the EM community. Notably, the tools can be slow to generate images that display information of interest. This means that by the time that a GIS image is created, it is already out of date. For example, during a terrorism-related exercise a GIS map was made with current information on an explosion at a public venue. During the time the map was being created, it was determined from new information that the explosion was actually in another location. When the maps with the erroneous information were delivered, the emergency managers began making decisions based on the incorrect location. The location discrepancy was not discovered for the majority of the exercise.

Other concerns with current GIS systems are that they are complicated and require a considerable level of expertise to operate. There is also a lack of a common geographic interface and iconography for information integration. Without common iconography, it is difficult to have a shared operational picture for situation awareness.

\subsection{Knowledge Transfer}

In the EM community, effective knowledge transfer is critical for operations, multiple handoffs, and shift changes during the course of an event. Knowledge transfer deals with communicating knowledge between both individuals and organizations across a range of domains and time scales (e.g., shift changes, best practices, etc.).

\subsubsection{Shift Changes}

Continuity of situation awareness is necessary, particularly during staff turnover. As new staff members come on, their knowledge of the situation needs to be updated. During shift changes, situation 
awareness can be degraded or lost (See Section 3.5 for information on situation awareness), especially if departing staff members are tired and do not provide a full accounting of the previous shift. This can happen for a variety of reasons such as:

- lack of face-to-face communication during shift change, resulting in loss of information

- lack of efficient means for shift personnel to share information and to pass on shift notes

- incoming staff having an incorrect or incomplete model of the system's state

- incoming staff being unaware of significant data or events

- incoming staff being unprepared to deal with impacts from previous events

- incoming staff failing to anticipate future events

- incoming staff lacking knowledge that is necessary to perform tasks

- incoming staff dropping or reworking activities that are in progress

- incoming staff creating an unwarranted shift in goals, decisions, priorities, or plans (Patterson et al. 2004).

According to an interview with law enforcement personnel, during the 2003 World Trade Organization meeting in Seattle, Washington, and subsequent rioting, many EM personnel were working very long hours in stressful circumstances. Even in normal conditions, staff members may forget to pass pertinent information to relief personnel-in physically and mentally exhausting situations, it is even more likely. The likelihood of forgetting pertinent information also increases when the time to complete shift change is short.

Shift changes and other situations requiring the transfer of duties and information between staff members often present challenges for situation awareness. Situation awareness can be degraded if incoming staff receive incomplete information from the previous shift. Providing solutions to address the reasons for inadequate information transfer would increase preparedness and situation awareness for incoming staff.

\subsubsection{Organizational Memory}

Organizational memory is the institutional knowledge held within an organization relating to its staff, operations, systems and structures, and best practices (McShane and Von Glinow 2000). Gaps exist in organizational memory as experienced staff members leave and new staff members join the organization; gaps also exist in the documentation and understanding of organizational lessons learned and best practices.

Few organizations have a standardized process for transferring the knowledge and expertise held by experienced personnel to other personnel. In the U.S. Coast Guard and U.S. National Guard, for example, personnel transfer occurs on a regular basis and is a normal part of operations, resulting in the frequent 
loss of expertise when staff members transfer. ${ }^{7}$ Situations where staff members are trained for a specific function but then rotate to a different unit, a frequent occurrence in military communities, result in inefficiencies from lost functionality. A similar situation occurs in organizations that do not cross train personnel—if a staff member is absent, the expertise is effectively lost.
"Online training, as it stands, is a poor substitute for experience." -Riley County, Kansas, Dept. of Emergency Management

Organizational memory also includes a higher-level

understanding of how the organization should operate such as documentation and dissemination of lessons learned and best practices. Organizations frequently do not store information during emergency response in a way that can be accessed in the future for evaluation. This includes reports such as plans, lessons learned, exercise evaluation, and after-action reports. Based on input from the Seattle Disaster Management Committee Strategic Working Group, which focuses on collaborative practices and policies to drive a coordinated response from the Seattle EM community, there is a need to organize and quickly retrieve existing plans for response to an emergency. A similar need was expressed by an evaluator of the High Plains Guardian Exercise, in which memorandums of understanding between agencies were not immediately available to clarify agencies’ individual responsibilities during the exercise.

Gaps associated with organizational memory are also related to extensive use of informal social networks in the EM community. Currently, most communication is informally conducted (via phone or face to face conversations). New personnel have not developed such a network and are unaware of who to contact. They may have to find a resource through trial and error, which wastes valuable time and potentially avoids the appropriate resource.

\subsubsection{Training}

There are a number of gaps associated with training in the EM community. These gaps primarily fall into two broad and overlapping categories: training for technical skills and training for cognitive skills. Current training technologies for both technical and cognitive skills do not adequately support knowledge transfer (Thomas et al. 2008). During the interviews, especially with SMEs that have a tactical expertise, ${ }^{8}$ it was acknowledged that current training does not have an adequate level of interactivity; does not allow students to practice realistic scenarios; lacks exercise-level simulations; does not train for sustained performance; and often does not account for various learning styles, technology, and/or social sensibilities.

"Most departments lack the staff they feel they need to adequately do emergency planning; there is no back-stopping. If one person is gone, there is no one left to do the job."

-Seattle Disaster Management Committee Strategic Working Group

Training via exercise is fundamental in acquiring and honing skills necessary in responding to an emergency. EM personnel must be able to rapidly comprehend emergent threats and act accordingly using appropriate interagency measures (Thomas et al. 2008). According to Thomas et al., proper response must involve interactive and resilient relationships between crisis responders. To be effective,

\footnotetext{
${ }^{7}$ In one example, a Coast Guard member was the only one in his unit who knew how to operate a specific piece of technology. Once the individual transferred, no one in the unit was trained to operate the technology and its utility was lost.

${ }^{8}$ SMEs from fire departments, police departments, and emergency operations centers
} 
these relationships need to be encouraged and developed before a disaster occurs. This point was reinforced in a number of interviews with SMEs. The need to create these relationships deals fundamentally with the level of trust that is needed in EM. This level of trust is gained by collaborating with other organizations outside of an event (i.e., training and exercise) to understand those organizations' responsibilities and competencies under

"Training is exceptionally difficult because there is no budget for it."

-FEMA Region $X$ working conditions.

SMEs $^{9}$ also expressed concern about agencies that have EM responsibilities but are not EM-specific agencies. The concern was that there is not sufficient cross training to preclude degradation of EM capabilities when those personnel who are responsible for an agency's EM function are not present.

This is even more serious in rural areas where local law enforcement agencies are responsible for logistics and planning. Because rural communities rely heavily on volunteer staff for other functions (e.g., fire fighting, paramedic, and other EM functions), it is even more critical that personnel are sufficiently cross-trained.

From interviews, ${ }^{10}$ it was identified that it is difficult to exercise often enough to adequately train for the breadth of emergency scenarios and for sustained performance of personnel. This is due in large part to the high cost of exercises in terms of time and resources related to managing and scheduling. Training outside of exercises was criticized by SMEs as not being realistic enough to effectively impart knowledge, did not accommodate various learning styles, and did not take into account the level of technological proficiency or social proficiency.

\footnotetext{
${ }^{9}$ SMEs from the Seattle Disaster Management Committee Strategic Working Group and public utilities

${ }^{10}$ SMEs from fire departments, police departments, and emergency operations centers
} 



\subsection{Conclusion}

The gaps identified in this report highlight key issues and challenges facing the EM community. The purpose of documenting these gaps is to gain a better understanding of the technology needs of the EM community and to work toward identifying future solutions to address these needs. By interviewing emergency management professionals and conducting a detailed literature review, PNNL researchers sought to develop a detailed understanding of these gaps and needs.

Research conducted for this effort revealed overarching gaps associated with information collection, sharing, and dissemination; communications; information security; analysis and decision support; situation awareness; and knowledge transfer. Access to data is a frequent challenge to information collection and dissemination, and information sharing between organizations often occurs only as a result of trusted personal relationships, limiting the ability to effectively use all information. Verbal communication remains the primary means of communication in an emergency, but capturing and structuring useful data contained in voice communication poses a significant challenge. Other communication gaps include the vulnerability of infrastructure to damage in an emergency and the challenge of collecting and disseminating information to and from the public in an emergency. Information security concerns related to both cyber threats and the inappropriate handling of sensitive information may limit collaboration in EM, creating gaps that impact effective operations.

Analysis and decision support are vital to EM, but are negatively impacted by the degradation or loss of relevant information due to information overload, information that is not in a useable format, or useful older information being prematurely replaced by newer information. Additional challenges and gaps impacting decision support include role ambiguity, limited resources for decision making, and difficulties in coordinating decision making. Gaps in situation awareness occur as a result of dynamic situations that result in a constantly changing emergency environment, difficulties in tracking the status of resources, and lack of access to and integration of geographic visualization systems. Finally, the area of knowledge transfer was identified as critical to EM, but it is impeded by difficulties in maintaining continuity of situation awareness through shift changes, the need to improve organizational memory, and gaps in technical and cognitive training.

The gaps and challenges outlined above address several topic areas relevant to EM and reveal abundant opportunities for improvement. By researching and identifying these needs, PNNL has developed a framework to better understand where technology can contribute to improved EM operations. 



\subsection{References}

DHS (U.S. Department of Homeland Security). 2004. National Response Plan. Department of Homeland Security, Washington, D.C.

DHS (U.S. Department of Homeland Security). 2008a. National Response Framework. Department of Homeland Security, Washington, D.C. Accessed at http://www.fema.gov/pdf/emergency/nrf/nrf-core.pdf on July 30, 2010.

DHS (U.S. Department of Homeland Security). 2008b. Mass Care, Emergency Assistance, Housing, and Human Services, ESF 6. Department of Homeland Security, Washington, D.C. Accessed at http://www.fema.gov/pdf/emergency/nrf/nrf-esf-06.pdf on July 30, 2010.

Endsley MR. 1995. "Toward a theory of Situation Awareness in Dynamic Systems.” The Journal of the Human Factors and Ergonomics Society 31(1):32-64.

GAO (U.S. Government Accountability Office). 2003. Geographic Information Systems. Government Accountability Office, Washington, D.C.

GAO (U.S. Government Accountability Office). 2005. Results-Oriented Government: Practices That Can Help and Sustain Collaboration Among Federal Agencies. Government Accountability Office, Washington, D.C.

GAO (U.S. Government Accountability Office). 2006. Hurrican Katrina: Better Plans and Exercises Needed to Guide the Military's Response to Ntural Disasters. Government Accountability Office, Washington, D.C.

GAO (U.S. Government Accountability Office). 2007a. Critical Infrastructure Protection: Progress Coordinating Government and Private Sector Efforts Varies by Sectors' Characteristics. Government Accountability Office, Washington, D.C.

GAO (U.S. Government Accountability Office). 2007b. Homeland Security: Preliminary Information on Federal Actions to Address Challenges Faced by State and Local Information Fusion Centers. Government Accountability Office, Washington, D.C.

GAO (U.S. Government Accountability Office). 2007c. Homeland Security: Observations on DHS and FEMA Efforts to Prepare for and Respond to Major and Catastrophic Disasters and Address Related Recommendations and Legislation. Government Accountability Office, Washington, D.C.

GAO (U.S. Government Accountability Office). 2008a. Emergency Management: Observations on DHS's Preparedness for Catastrophic Disasters. Government Accountability Office, Washington, D.C.

GAO (U.S. Government Accountability Office). 2008b. National Disaster Response: FEMA Should Take Action to Improve Capacity and Coordination between Government and Voluntary Sectors. Government Accountability Office, Washington, D.C. 
GAO (U.S. Government Accountability Office). 2008c. Homeland Security: First Responders’ Ability to Detect and Model Hazardous Releases in Urban Areas Is Significantly Limited. Government Accountability Office, Washington, D.C.

GAO (U.S. Government Accountability Office). 2009a. Emergency Communication: Vulnerabilities Remain and Limited Collaboration and Monitoring Hamper Federal Efforts. Government Accountability Office, Washington, D.C.

GAO (U.S. Government Accountability Office). 2009b. Urban Area Security Initiative: FEMA Lacks Measures to Assess How Regional Collaboration Efforts Build Preparedness Capabilities. Government Accountability Office, Washington, D.C.

GAO (U.S. Government Accountability Office). 2009c. Information Sharing: Federal Agencies Are Sharing Border and Terrorism Information with Local and Tribal Law Enforcement Agencies, but Additional Efforts Are Needed. Government Accountability Office, Washington, D.C.

GAO (U.S. Government Accountability Office). 2009d._Biosurveillance: Developing a Collaboration Strategy Is Essential to Fostering Interagency Data and Resource Sharing. Government Accountability Office, Washington, D.C.

GAO (U.S. Government Accountability Office). 2009e. Emergency Management: Actions to Implement Select Provisions of the Post-Katrina Emergency Management Reform Act. Government Accountability Office, Washington, D.C.

GAO (U.S. Government Accountability Office). 2009f. Vulnerabilities Remain and Limited Collaboration and Monitoring Hamper Federal Efforts. Government Accountability Office, Washington, D.C.

GAO (U.S. Government Accountability Office). 2009g. Emergency Communications: National Communications System Provides Programs for Priority Calling, but Planning for New Initiatives and Performance Measurement Could Be Strengthened. Government Accountability Office, Washington, D.C.

GAO (U.S. Government Accountability Office). 2009h. Wildland Fire Management: Federal Agencies Have Taken Important Steps Forward, but Additional, Strategic Action Is Needed to Capitalize on Those Steps. Government Accountability Office, Washington, D.C.

GAO (U.S. Government Accountability Office). 2010a. Cybersecurity: Continued efforts are still needed to protect infrastructure. Government Accountability Office, Washington, D.C.

GAO (U.S. Government Accountability Office). 2010b. Combatting Nuclear Terrorism: Actions Needed to Better Prepare to Recover from Possible Attacks Using Radiological or Nuclear Materials.

Government Accountability Office, Washington, D.C.

GAO (U.S. Government Accountability Office). 2010c. Homeland Defense: Planning, Resourcing, and Training Issues Challenge DOD's Response to Domestic Chemical, Biological, Radiological, Nuclear, and High-Yield Explosive Incidents. Government Accountability Office, Washington, D.C. 
GAO (U.S. Government Accountability Office). 2010d. Cybersecurity: Progress Made but Challenges Remain in Defining and Coordinating the Comprehensive Initiative. Government Accountability Office, Washington, D.C.

Gorman JC, NJ Cooke, and JL Winner. 2006. “Measuring team situational awareness in decentralized command and control environements.” Ergonomics 49(12\&13):1312-1325.

Manoj BS and AH Baker. 2007. “Communications Challenges in Emergency Response.” Communications of the ACM 50(3):51-53.

McShane SL and MA Von Glinow. 2000. Organizational Behavior: Emerging Realities for the Workplace Revolution. Richard D. Irwin, Inc., New York, New York.

Patterson ES, EM Roth, DD Woods, R Chow, and JO Gomes. 2004. "Handoff strategies in setting with high consequences for failure: lessons for health care operations.” International Journal for Quality in Health Care 16(2):125-132.

Poulsen K. October 23, 2007. "Firsthand Reports from California Wildfires Pour Through Twitter." Threat Level. Accessed at http://www.wired.com/threatlevel/2007/10/firsthand-repor/ on July 30, 2010.

Thomas K, K Hallock, and PR Bergethon. 2008. “The Need for Cross Discipline Awareness and Interoperability in the First Responder and Emergency Management Communities.” In proceedings of The Cornwallis Group XIII: Analysis of Societal Conflict and Counter Insurgency. Cornwallis Park, Nova Scotia, Canada. 



\section{Appendix A}

\section{Interview Focus and Sample Questions}





\section{Appendix A}

\section{Interview Focus and Sample Questions}

Our main focus is in understanding how data visualization, models, and simulations could improve the process and information flow for emergency responders. How can we give them the information they need when they need it? Here are the main areas, pulled from NIMMS, we've identified that we want to observe and ask about to better define potential opportunities in this space. A prompt is provided for directing the interview, but feel free to dive into topics that seem especially important as the interview progresses.

\section{A.1 Preparedness}

\section{A.1.1 Planning}

- What planning activities do you perform in your role? Do you have budget resource and schedule responsibilities? How are those performed?

- Are you or the people you are responsible for involved in any preparedness activities like being on call and available on scene in $\mathrm{X}$ number of minutes. How do you prepare for that, and how is it measured?

\section{A.1.2 Training}

- Tell me about the training process for your role or the people you are responsible for. How long does it take, and what are the procedures?

- What types of simulations do you use?

- How effective are new employees once trained?

- What's the biggest difference between a veteran and a newly trained rookie?

\section{A.2 Communications and Information Management}

\section{A.2.1 Communication}

- What is communication like today? How do you communicate to peers, management, direct reports, and/or other types of responders?

- What is communication like in an emergency response? How is it different from day to day activities?

- How do you find people you know and don’t know?

- What problems or issues do you have with this system?

- Have you had to communicate with the public? What is that process like? How do you know what information can be communicated? Who is involved in that decision? 


\section{A.2.2 Information Management}

- How do you access information you need to perform your job? What are the tool sets you use?

- What kind of information do you have access to? What information do you wish you had and when?

- Describe a time when you didn't get the information you needed or when the information you got was incorrect and how could it have been different.

- How correct is the information you get? How do you think it could be improved?

\section{A.3 Resource Management}

- Are you responsible for resources like equipment or people? What tools do you use to manage them?

- How do you know the status of an asset? (I.E., is a piece of equipment online or is a member of your personnel current on certifications?) What happens if they are not? How is this incorporated into your preparedness strategy?

- What is the procurement process like for buying new equipment or for borrowing from another jurisdiction? How is it different in an emergency situation?

\section{A.4 Command and Management}

- What are some of your day-to-day job activities? What processes and best practices do you follow?

- How does that change in an emergency response? What is the process for your role in an emergency? How do you get the call? Who do you have to call? Is there a process for escalation?

- Describe an emergency you responded to. What types of decisions did you have to make? What tools did you use to make those decisions?

- Have you ever had to manage and coordinate across multiple agencies? What was that like, and what can be improved? How was authority established?

\section{A.5 Ongoing Management and Maintenance}

- How do you keep your skills and resources current and up to date?

- What do you, if anything, around strategic research and development inside your field? How far out in the future do you look in this analysis?

- How do you monitor efficiency and efficacy of your resources and processes? Is there a compliance process? Who manages that and how is it done?

- What is the transition process like in an emergency response when a longer time is required across agencies?

\section{A.6 Debrief}

Give the participants time to ask questions of you. Tell them if they have any further questions they can contact you directly, and ask them if you can do the same. Leave a calling card and thank them for their time. 